Marie I. KaISER

\title{
Why It Is Time to Move Beyond Nagelian Reduction
}

\section{INTRODUCTION}

In this paper I argue that it is finally time to move beyond the Nagelian framework and to break new ground in thinking about epistemic reduction in biology. I will do so, not by simply repeating all the old objections that have been raised against Ernest Nagel's classical model of theory reduction. ${ }^{1}$ Rather, I grant that a proponent of Nagel's approach can handle several of these problems but that, nevertheless, Nagel's general way of thinking about epistemic reduction in terms of theories and their logical relations is entirely inadequate with respect to what is going on in actual biological research practice.

I start with an overview of the long "success story" of the Nagelian account, which I think has not really found an ending yet (section 2). Then I reveal the inadequacy of the Nagelian framework with respect to biology (section 3) by arguing that Nagel focuses on the wrong relata of the relation of epistemic reduction (section 3.2) and on the wrong kind of issues, namely on formal and not on substantive issues (section 3.3). My argumentation is based on certain methodological assumptions about how to develop an adequate account of epistemic reduction (section 3.1), which I specify by unfolding three criteria of adequacy that an account of epistemic reduction in biology must satisfy.

\section{The Dominance of the Nagelian Model - A Brief History}

The question about the reduction of the biological realm to, for instance, the physical realm is an old one. Reduction was an implicit topic of the mechanistic philosophy in the $16^{\text {th }}$ and $17^{\text {th }}$ century and it was controversially disputed in the debate about vitalism in the $19^{\text {th }}$ and early $20^{\text {th }}$ century. In more recent years, when philosophy of biology emerged as a separate discipline in the 1960s/1970s the question whether biological theories can be reduced to molecular and in the end to physical theories was among the first issues disputed. Reductionism in biology became a central topic due to the impressive growth and development of molecular biology. Of particular interest was the question of whether classical genetics can

1 Cf. Ernest Nagel, The Structure of Science. Problems in the Logic of Scientific Explanation. London: Routledge 1961. 
be reduced to molecular biology. This special case was seen as a test case for the reduction of biology to physics in general. ${ }^{2}$

A few years before the debate about reduction in biology emerged, Nagel had published his The Structure of Science, in which he developed his formal model of theory reduction. In the spirit of logical empiricism, Nagel characterizes reduction as a deductive relation that holds between scientific theories, which he takes to be sets of law statements. In line with the deductive-nomological (D-N) model of explanation ${ }^{3}$, Nagel conceived reduction as a special case of explanation. For reduction to occur two conditions must be satisfied: The reduced theory has to be derived from the reducing theory ("condition of derivability")). This presupposes that the reduced and the reducing theory either contain the same terms (in case of homogenous reduction) or that the former can be connected to the latter (in cases of heterogeneous reduction) via so called 'bridge laws' or, more neutrally, 'correspondence statements' ("condition of connectability"5). It should be acknowledged that Nagel contributed much more to the debate about reduction than this. For instance, he also proposed several non-formal conditions for distinguishing trivial from non-trivial cases of reduction ${ }^{6}$, discussed the issues of emergence ${ }^{7}$ and "mechanistic explanation" in biology ${ }^{8}$, and identified different reasons why the whole can be more than the sum of its parts ${ }^{9}$. Nonetheless, the subsequent debate about Nagel's account focused on the formal conditions he identifies in his chapter on theory reduction. Although Nagel developed his formal model solely on basis of an example from physics (i.e. the reduction of thermodynamics to statistical mechanics), the early philosophers of biology considered it to be an adequate understanding of what epistemic reduction ${ }^{10}$ in the sciences in general is and, thus, tried to apply it to biology.

2 Cf. Philip Kitcher, "1953 and All That: A Tale of Two Sciences”, in: Philosophical Review 93, 1984, pp. 335-373 and Alexander Rosenberg, The Structure of Biological Science. Cambridge: Cambridge University Press 1985.

3 Cf. Carl Hempel, Paul Oppenheim, "Studies in the Logic of Explanation“, in: Philosophy of Science 15, 2, 1948, pp. 135-175.

4 Nagel, The Structure of Science, pp. 354.

5 Ibid., pp. 354.

6 Cf. ibid., pp. 358-366.

7 Cf. ibid., pp. 366-380.

8 Cf. ibid., pp. 398-446.

9 Cf. ibid., pp. 380-397.

10 With 'epistemic reduction' I refer to the reduction of one body of knowledge (or parts of it like theories, explanations, methods, etc.) of a certain scientific discipline, e.g. biology, to another body of knowledge (or parts of it) of a different scientific discipline, e.g. physics. Epistemic reduction should be clearly distinguished from ontological reduction, which is the reduction of ontological entities of one kind (like objects, properties, facts, etc.), e.g. biological token objects, to ontological entities of another kind, e.g. physical token objects. In short, ontological reduction is a relation between things in the world and epistemic reduction is a relation between parts of our knowledge 
It quickly became clear that Nagel's account not only had to face many general problems ${ }^{11}$, but that biology provides special obstacles for Nagelian reduction as well. In short: The objections were that neither the bridge laws that are needed to connect the terms of biological and physical theories nor the laws that constitute the units to be reduced, i.e. theories, are available in biology. ${ }^{12}$ First, because evolution by natural selection is blind to structural differences with similar functions, most existing biological types of entities are multiply realized on the physical level. ${ }^{13}$ For instance, the wings of different species of birds (let alone those of mammals and insects) vary strongly with respect to their structure and material composition although almost all of them share the same function, i.e., they enable their bearers to fly. The multiple realization of biological types makes it very difficult to establish those connections between the terms of biological theories (e.g. classical genetics) and physical or molecular theories (e.g. molecular biology) that are needed for reduction in the Nagelian sense. Second, another obstacle for a neat application of Nagel's model to biology is his assumption that theories are sets of law statements. The generalizations that can be found in biology (e.g. Mendel's laws of segregation and independent assortment) seem to be far away from describing laws of nature in the classical, strict sense. They typically have

about these things in the world. Nagelian theory reduction is a special case of epistemic reduction (other cases are explanatory and methodological reduction) because according to Nagel the relation of reduction holds between representational entities, i.e. theories. This is compatible with the claim that Nagel's regards bridge laws as stating identities or relations among extensions, i.e. as ontological links (although this is by no means clear, cf. for example Peter Fazekas, "Reconsidering the Role of Bridge Laws in Inter-Theoretical Reductions”, in: Erkenntnis 71, 2009, pp. 303-322). Even if bridge laws are interpreted as stating ontological links, they are still linguistic entities (that represent relations that exist in the world) and not the relations in the world themselves.

11 For instance, Frederick Suppe, Ken Waters and others criticized the reliance of Nagel's account on a syntactic view of theories (cf. Frederick Suppe, The Structure of Scientific Theories. $2^{\text {nd }}$ ed. Urbana: University of Illinois Press 1977 and Kenneth Waters, "Why the Antireductionist Consensus Won't Survive the Case of Classical Mendelian Genetics”, in: PSA 1990, 1, 1990, pp. 125-139). Paul Feyerabend attacked Nagel's model by claiming the incommensurability of the meaning of the theoretical terms of the reduced and reducing theory (cf. Paul Feyerabend, "Explanation, Reduction and Empiricism”, in: Herbert Feigl and Grover Maxwell (Eds.), Scientific Explanation, Space, and Time, Minneapolis: University of Minnesota Press 1962, pp. 28-97). Finally, Schaffner pointed out that in most cases of theory reduction the reduced theories first need to be corrected before they can be derived from the reducing theory (cf. Kenneth Schaffner, "Approaches to Reduction", in: Philosophy of Science 34, 1967, pp. 137-147 and "The Watson-Crick Model and Reductionism”, in: British Journal for the Philosophy of Science 20, 1969, pp. 325-348).

12 Cf. for example Kitcher, loc. cit.

13 For a detailed elaboration of this point see, for instance, Alexander Rosenberg, "How Is Biological Explanation Possible?”, In: British Journal for Philosophy of Science 52, 2001, pp. 735-760. 
exceptions, are restricted in scope, and it can be argued that they are historically contingent. ${ }^{14}$ This led many philosophers of biology to the conclusion: no laws in biology, hence, no cases of reduction in biology. The result was the formulation of the "antireductionist consensus"15. About 20 years after the reductionism debate in the philosophy of biology had emerged it seemed as if everybody had become an antireductionist. ${ }^{16}$ Even philosophers with strong reductionistic intuitions like Alexander Rosenberg gave up the hope that biology can be reduced to physics. ${ }^{17}$

It is important to note that during these 20 years and up to the 1990s the majority of philosophers took the obstacles with applying Nagel's model to biology to reveal the non-existence of reduction in this field and to support the incorrectness of reductionism in biology. Most of them did not choose the alternative option to question that Nagel's account is, in principle, the adequate way of thinking about reduction..$^{18}$ It was common practice to disagree about the details of the Nagelian model of theory reduction and to call for revisions. Many philosophers, most notably Kenneth Schaffner, tried to overcome the problems of Nagel's account by developing it further. ${ }^{19}$ However, at that time hardly anybody questioned Nagel’s

14 Cf. John Beatty, “The Evolutionary Contingency Thesis”, in: Gereon Wolters, James Lennox (Eds.), Concepts, Theories, and Rationality in the Biological Sciences. Pittsburgh: University of Pittsburgh Press 1995, pp. 45-81.

15 Waters, "Why the Antireductionist Consensus Won't Survive the Case of Classical Mendelian Genetics", loc. cit., pp. 125. It is important to note that, contrary to the situation in the philosophy of mind, the reductionism debate in the philosophy of biology is a dispute about the frequency or possibility of epistemic reduction and not of ontological reduction. Ontological reductionism, at least in its weak version of a token-token physicalism, is the (often implicit) consensus in the philosophy of biology. However, this does not mean that it is impossible or fruitless to analyze ontological reduction or to dispute about ontological reductionism in biology. The epistemic questions are just taken to be more controversial than the ontological ones.

16 Notable exceptions are Ruse (Michael Ruse, "Reduction in Genetics", PSA 1974, 1976, pp. 633-651.) and Schaffner (cf. Kenneth Schaffner, The Watson-Crick Model and Reductionism and "Reductionism in Biology: Prospects and Problems", in: PSA 1974, 1976, pp. 613-632).

17 According to Rosenberg's view in the 1990s the impossibility of reductionism in biology inevitably leads to an instrumentalist interpretation of biological theorizing ("If reductionism is wrong, instrumentalism is right.” Alexander Rosenberg, Instrumental Biology or the Disunity of Science. Chicago: University of Chicago Press 1994, pp. 38 ) and to the abandonment of the unity of science above the level of physics. In the 2000s Rosenberg gave up this position again and became one of the few defenders of (epistemic) reductionism in biology.

18 Among the few exceptions were Wimsatt (cf. William Wimsatt, "Reductive Explanation: A Functional Account”, in: PSA 1974, 1976, pp. 671-710) and Hull (David Hull, Philosophy of Biological Science. New Jersey: Prentice-Hall Inc. 1974).

19 Schaffner calls his revised version of Nagel's account 'general reduction-replacement model'. For a summary about how Schaffner supposes to cope with the problems of the Nagelian model see Kenneth Schaffner, Discovery and Explanation in Biology and Medicine. Chicago/London: University of Chicago Press 1993, chapter 9. 
general way of thinking about reduction. In other words, most philosophers accepted the following two theses:

(1) The adequate units of the relation of reduction are theories (whether they are conceived as sets of law statements or not, whether the theories need to be corrected before being reduced or not, and whether one adopts a syntactic view of theories or not). ${ }^{20}$

(2) The relation of reduction is a relation of logical derivation (whether this means exact derivability or something weaker and whether the bridge laws that are necessary for the derivation are conceived as identity statements or not). ${ }^{21}$

The widespread acceptance of this general way of thinking about reduction in terms of theories and logical relations prevailed in the debate for a surprisingly long time. This is especially true for discussions that are not centered on but rather pick up the issue of reduction..$^{22}$ The most instructive example is Rosenberg, who nowadays explicitly argues for the need to abandon the Nagelian understanding of reduction ${ }^{23}$ but, in the 1980s and 1990s, claimed that it "sounds suspicious to

20 Although some philosophers questioned the syntactic view of theories and called for a less formal alternative, up to the late 1990s almost nobody questioned the general thesis that theories are the adequate units of reduction. For instance, in his influential paper from 1990 Waters objected to Nagel's model of theory reduction but merely demanded the "reformulation of theoretical reduction" (Waters, Why the Antireductionist Consensus Won't Survive the Case of Classical Mendelian Genetics, pp. 136). Nowadays Waters explicitly criticizes the concepts of "theoretical reduction" and "layer-cake antireduction" and the exclusive focus on theoretical developments in biology they imply (cf. Kenneth Waters, "Beyond Theoretical Reduction and Layer-Cake Antireduction: How DNA Retooled Genetics and Transformed Biological Practice", in: Michael Ruse (Ed.), The Oxford Handbook of the Philosophy of Biology. Oxford: Oxford University Press 2008, pp. 238-262).

21 At this point I want to emphasize that there, in fact, were a few philosophers of biology (most notably, David Hull, "Informal Aspects of Theory Reduction”, in: PSA 1974, 1976, pp. 653-670 and Wimsatt, "Reductive Explanation: A Functional Account”, loc. cit.) who early objected to this second thesis, i.e. Nagel's and Schaffner's presupposition that a model of theory reduction should focus on formal issues and reconstruct reduction as a relation of logical derivation.

22 One reason for the long survival of the Nagel-Schaffner model of theory reduction is that there was simply no popular alternative available, which could have replaced the thinking about reduction in terms of theories and logical relations. I think Wimsatt's functional analysis of reduction (cf. Wimsatt, "Reductive Explanation: A Functional Account”, loc. cit.), which focuses on reductive explanations and mechanisms, had the potential to replace it but his account was, perhaps, not catchy and comprehensible enough.

23 Cf. Alexander Rosenberg, Darwinian Reductionism. Or, How to Stop Worrying and Love Molecular Biology. Cambridge: University of Chicago Press 2006, pp. 40. 
change the standards of reduction"24 and conceived the alternative option of abandoning reductionism altogether as the "more reasonable"25 option.

During the last 15 years more and more philosophers rejected the NagelSchaffner account and developed alternative ways of thinking about epistemic reduction in biology. ${ }^{26}$ However, many opponents of the Nagelian approach do not put effort in elaborating an alternative view of epistemic reduction but rather argue for the abandonment of the focus on reduction altogether. ${ }^{27}$ Despite these new developments, there clearly are philosophers, who adhere to the concept of reduction because they think it is an important conceptual tool for capturing many aspects of biological practice (or who think it is a philosophically interesting or fruitful concept one should not dismiss to easily). And many of these philosophers are far away from having given up thinking about reduction in terms of theories and logical derivation. ${ }^{28}$

24 Rosenberg, "The Structure of Biological Science", loc. cit., p. 110.

25 Rosenberg, "Instrumental Biology or the Disunity of Science", loc. cit., p. 22.

26 See e.g. Sahotra Sarkar, "Models of Reduction and Categories of Reductionism", in: Synthese 91, 1992, pp. 167-194; Genetics and Reductionism. Cambridge: Cambridge University Press 1998; Molecular Models of Life. Philosophical Papers on Molecular Biology. Cambridge: MIT Press 2005; William Wimsatt, Reductive Explanation: A Functional Account; Re-Engineering Philosophy for Limited Beings: Piecewise Approximations to Reality. Cambridge: Harvard University Press 2007; Rosenberg, Darwinian Reductionism; William Bechtel, Discovering Cell Mechanisms. The Creation of Modern Cell Biology. Cambridge: Cambridge University Press 2006; and Mental Mechanisms. Philosophical Perspectives on Cognitive Neuroscience. New York/London: Taylor and Francis Group 2008.

27 See e.g. Carl Craver, "Beyond Reduction: Mechanisms, Multifield Integration and the Unity of Neuroscience", in: Studies in the History and Philosophy of Biological and Biomedical Sciences 36, 2005: pp. 373-395; Carl Craver, Explaining the Brain. Mechanisms and the Mosaic Unity of Neuroscience. Oxford: Clarendon Press 2007; Sandra Mitchell, Biological Complexity and Integrative Pluralism. New York: Cambridge University Press 2003; Sandra Mitchell, Unsimple Truths. Science, Complexity, and Policy. Chicago/London: University of Chicago Press 2009; Sandra Mitchell and Michael Dietrich, "Integration without Unification: An Argument for Pluralism in the Biological Sciences", in: American Naturalist 168, 2006, pp. 73-79; Lindley Darden, "Relations Among Fields: Mendelian, Cytological and Molecular Mechanisms", in: Studies in History and Philosophy of Biological and Biomedical Sciences 36, 2005, pp. 357-371; Lindley Darden and Nancy Maull, “Interfield Theories”, in: Philosophy of Science 44, 1977, pp. 43-64.

28 See e.g. Kenneth Schaffner, Discovery and Explanation in Biology and Medicine; "Reduction: The Cheshire Cat Problem and a Return to Roots”, in: Synthese 151, 2006, pp. 377-402; John Bickle, Psychoneural Reduction: The New Wave. Cambridge: MIT Press 1998; John Bickle, Philosophy and Neuroscience: A Ruthlessly Reductive Account, Dordrecht: Kluwer Academic Publishers 2003; John Bickle, "Reducing Mind to Molecular Pathways: Explicating the Reductionism Implicit in Current Cellular and Molecular Neuroscience”, in: Synthese 151, 2006, pp. 411-434; Ulrich Krohs, Eine Theorie Biologischer Theorien. Status und Gehalt von Funktionsaussagen und informationstheoretischen Modellen. Berlin: Springer 2004; Colin Klein, "Reduction 
My main thesis in this paper is that it is finally time to leave Nagel's general way of thinking about reduction behind. However, I think this should not lead us to abandon the idea of reduction altogether. Rather, we should accompany authors like Sahotra Sarkar and William Wimsatt in their search for an adequate understanding of what epistemic reduction in biology really is. Thinking about reduction in terms of theories and the logical relation between statements has dominated the debate for too long. Instead of imposing an ill-fitting model on biology, we should develop a new account of epistemic reduction that "makes contact with real biology" (to use Rosenberg's words) and captures the diversity of reductive reasoning strategies present in current biological research practice. ${ }^{29}$ Such an improved understanding will also disclose the importance as well as the limits of epistemic reduction in biology.

\section{The Inadequacy of the Nagelian Account}

In this section I do not want to echo the old criticism that has been put forward against Nagel's formal model of theory reduction in the early reductionism debate to reveal its general problems and its inapplicability to biology. This is the reason why my critique is focused on Nagel's general way of thinking about epistemic reduction (see section 2) and abstract away from those details of Nagel's model that have turned out to be highly problematic. First, I grant that one could give up the concept of a strict law and adopt a more moderate account of what a scientific law is. For instance, one could allow laws to be ceteris paribus laws ${ }^{30}$ or adopt the concept of a "pragmatic law"31. This would allow one to claim that there exist genuine biological laws and, thus, that the relata for Nagelian reduction, namely theories as sets of law statements, are available. Second, I admit that one could

Without Reductionism: A Defence of Nagel on Connectability”, in: The Philosophical Quarterly 59, 2009, pp. 39-53; Foad Dizadji-Bahmani, Roman Frigg, Stephan Hartmann, “Who Is Afraid of Nagelian Reduction?”, in: Erkenntnis 73, 2010, pp. 393-412; etc.

29 To be clear: This search for a new account of epistemic reduction cannot be the step of a desperate reductionist who seeks an understanding of reduction that allows him, finally, to defend reductionism in biology. One can speculate that this is exactly the way Rosenberg gets to his understanding of explanatory reduction, namely, that it allows him to defend Darwinian Reductionism (which is a specific version of explanatory reductionism). I think it is important to resist this temptation. An account of epistemic reduction should not reflect the wishes or ideals of philosophers. Rather, its search should be motivated by the aim to understand and reconstruct the various reductive reasoning practices characteristic for contemporary biological research.

30 Cf. for instance Marc Lange, Natural Laws in Scientific Practice. Oxford: Oxford University Press 2000

31 Sandra Mitchell, "Pragmatic Laws”, in: Philosophy of Science 64, 1997, pp. 468-479 and "Biological Complexity and Integrative Pluralism", loc. cit. 
simply abandon Nagel's claim that theories must consist of law statements and allow each kind of general statements formulated in a formal language, i.e., first order logic. Third, one could go even further and abandon the "syntactic view" or "received view" 32 of theories and with it the requirement that theories must be formulated as statements in first-order logic. Alternatively, one could argue for a "semantic view" ${ }^{33}$ of theories, according to which theories are families of models formalized in set theory. However, on closer inspection (see section 3.2), this step turns out to be highly problematic as it leads the Nagelian model too far away from its core ideas. Forth, I allow the changes of the Nagelian model Schaffner made in his "general reduction-replacement model"34. In line with Schaffner one could claim that reduction (in the revised Nagelian sense) also captures cases in which not the original theories themselves, but rather corrected versions of them are derived from each other. Finally, I grant that one can abandon the strong claim that bridge laws must be factual statements that express identity relations (though it is not at all clear whether Nagel holds this strong view ${ }^{35}$ ). Even if they are taken to be factual claims (and not e.g. mere stipulations, i.e. conventions) it is left open which ontological relation they express (for instance, mere correlations, necessary nomic connections, constitutional relations, identity relations, etc. ${ }^{36}$ ).

If a defender of the Nagelian account relinquishes all these problematic assumptions, what is left over is Nagel's general way of thinking about epistemic reduction, which can be characterized by the two theses introduced in the last section: first, the adequate units of the relation of reduction are theories and, second, the relation of reduction is a relation of logical derivation. My claim is that even this very moderate, thin version of the Nagelian account of reduction is deeply flawed. In the next sections I will reveal several reasons why it is inadequate to think about epistemic reduction in biology in terms of theories and the logical relations between them. The general line of my argument will be that a formal model of theory reduction does neither capture the most important cases of epistemic reduction in biology nor does it account for the diversity of reductive reasoning strategies present in current biological research practice. This leaves us with an account of epistemic reduction that reflects the ideals of some philosophers but that is unconnected with real biological practice because it has no or at least a very

32 Frederick Suppe, "Understanding Scientific Theories: An Assessment of Developments, 1969-1998“, in: Philosophy of Science 67, 2000, pp. 102-115, p. 102. See also Paul Thompson, The Structure of Biological Theories. Albany: State University of New York Press 1989.

33 Frederick Suppe, “The Structure of Scientific Theories”, loc. cit. and The Semantic Conception of Theories and Scientific Realism. University of Illinois Press: Chicago 1989.

34 Cf. Schaffner, "Approaches to Reduction”, loc. cit.; "The Watson-Crick Model and Reductionism”, loc. cit.; "Reductionism in Biology: Prospects and Problems”, loc. cit.; and "Discovery and Explanation in Biology and Medicine", loc. cit.

35 Cf. Nagel, “The Structure of Science”, loc. cit., pp. 354-358.

36 See also Dizadji-Bahmani et al., "Who Is Afraid of Nagelian Reduction?”, loc. cit. 
restricted range of application. However, before I can move on it is necessary to make a few methodological clarifications.

\subsection{How to Develop an Account of Epistemic Reduction}

Why care about biological research practice in the first place? Why not stick to Nagel's formal model of theory reduction and view it as an ideal that does not need to be realized in biological practice? Schaffner, for instance, chooses this route and admits that theory reduction is "peripheral" to biological practice and should be regarded as a mere "regulative ideal" 37 . I think that these two options - on the one hand, developing an account of epistemic reduction that captures actual biological practice and, on the other hand, analyzing epistemic reduction without caring about what epistemic reduction in practice is - are best seen as completely different projects. Those philosophers who want to understand what biologists actually do and how biological research practice really works will not be satisfied with a philosophical account that merely reflects the wishes or ideals of philosophers but does not capture what is really going on in biology itself. They will judge accounts of the second kind as descriptively inadequate and, probably, not continue thinking about them at all. Philosophers who pursue a project of the second type do not share the goal of capturing and understanding actual biological research practice but rather endorse other values of a philosophical account (for example, the fact that it captures certain philosophical or common sense intuitions, its suitability for a broader philosophical, for instance metaphysical, theory, its explanatory force, etc.). In the radical version of this kind of project descriptive adequacy is simply abandoned as a criterion of adequacy. The focus lies exclusively on analyzing reduction in principle. What characterizes reduction in practice is ignored.

However, looking at how philosophy of science is presently carried out reveals two points: first, although these two kinds of projects can be distinguished from each other they are, in fact, two end points of a continuum and, second, projects of the second type (at least in its radical version) are rare. Consider the first point. Since projects of the first type are philosophical projects they are more than mere descriptions of scientific practice. Rather they are actively pursued reconstructions that involve normative decisions of various kinds (in a broad sense, e.g. the choice of paradigmatic cases) and that can also result in normative claims about how science ideally should be carried out. On the other hand, only few philosophers, who pursue a project of the second type make claims about how science ideally should work without even having a quick glance at how science actually works. Thus, most projects are, in fact, located somewhere in the middle ground between the two extremes of the continuum. This leads us to the second point. Especially

37 Schaffner, "Discovery and Explanation in Biology and Medicine”, loc. cit., pp. 508513. In recent years even Schaffner has disavowed from his peripherality thesis and adopted a less spectacular view about reduction (cf. Schaffner, Reduction: The Cheshire Cat Problem and a Return to Roots). 
in philosophy of biology, most projects belong to (a moderate version of) the first type. Philosophers want to understand, for example, how the success and failure of explanation in different biological disciplines is in fact evaluated, why molecular research in various areas is as important as it is, which different roles models play in actual biological research practice, and how biologists de facto estimate the scope of biological generalizations. However, there are philosophers of science who are not primarily interested in capturing and understanding actual scientific practice. Their goal is to develop a view about science or about a specific element of science (like explanation, causation, confirmation, law, etc.) that is adequate because it captures certain philosophical intuitions, that is in line with a certain general philosophical picture or that has special explanatory force. But even the projects of this second kind are rarely pursued without relying (at least partially) on a view about how science really works and why it is actually successful. This is not surprising since it seems weird to make claims about how science ideally should work or certain elements of scientific practice like explanation and reduction should be understood without taking into account how science actually works and what scientific explanations and reductions in fact are. However, here I do not want to argue for this claim at length. Rather, I want to be explicit about where I stand and on basis of which criteria of adequacy I attack Nagel's general way of thinking about epistemic reduction.

My paper is concerned with the question whether Nagel's formal model of theory reduction is convincing if it is understood as a project of the first kind. Thus, the question is whether thinking about epistemic reduction in terms of theories and the logical relations between them "saves the phenomena (about the biological sciences)" (to borrow Bas van Fraassen's way of talking) and helps to understand what is going on in actual biological research practice. According to my view, there exist two criteria of adequacy on whose basis the quality of any philosophical account of epistemic reduction (pursued as a project of the first type) is judged: A model of epistemic reduction should

(1) capture and help to understand the cases of epistemic reduction that actually occur in current biological research practice, rather than focusing on epistemic reduction that can only be achieved in principle. In addition, it should

(2) account for the diversity and complexity of the cases of epistemic reduction that are present in contemporary biology.

In the following sections I will argue why Nagel's general way of thinking about epistemic reduction in terms of theories and logical relations fails to satisfy these two criteria and, thus, should be assessed as inadequate to biology.

\subsection{Theories as Relata of Reduction}

One kind of objection that has been frequently put forward against Nagel's approach concerns the non-existence or misrepresentation of the relata of reduction. 
Nagel argues that the relation of reduction holds between theories, which he conceives as systems of statements, containing law statements and being formalized in first order logic. ${ }^{38}$ In the subsequent discussion about the structure of scientific theories this view is referred to as the syntactic conception of theories. Nagel's account of what the relata of reduction are encounters several objections: first, it can be argued that the relata, i.e., theories containing law statements, do not exist since there are no strict laws in biology. Second, one can claim that Nagel misrepresents the relata of reduction because scientific theories in general and biological theories in particular do not satisfy the demands of the syntactic view. Rather, theories (in biology) are to be understood as families or sets of models meeting specific settheoretic conditions. ${ }^{39}$

As stated at the beginning of section 3, I am willing to allow several steps a proponent of Nagel's model could take in order to meet these objections and defend a modified version of the Nagelian account - at least if these modifications are carried out in a convincing manner. To counter the first objection, one could either argue for a more moderate conception of a 'law', according to which there exist genuine laws also in biology ${ }^{40}$ or one could abandon Nagel's requirement that theories must contain law statements. However, it should be noted that the second option is highly problematic since Nagel conceives reduction to be a special case of explanation and explanation, according to the D-N model Nagel adopts, presupposes the availability of lawlike generalizations. Thus, it seems as if only the first option is accomplishable.

With respect to the second objection, a defender of Nagel's model of reduction could give up the syntactic view of scientific theories and adopt the alternative, semantic conception. The possibility of making this move is one reason why Foad Dizadji-Bahmani, Roman Frigg, and Stephan Hartmann want to convince us not to be afraid of Nagelian reduction anymore. The syntactic view is "unnecessary" to get Nagel's account "off the ground". We can replace first order logic "with any formal system that is strong enough to do what we need it to do" ${ }^{41}$. They seem to

38 Cf. Ronald Giere, Explaining Science: A Cognitive Approach. Chicago: University of Chicago Press 1988. For details about Nagel's view of theories compare Chapter 5 "Experimental Laws and Theories" and 6 "The Cognitive Status of Theories" of his "The Structure of Science", loc. cit.

39 Many philosophers of biology have embraced this semantic view of theories, especially with respect to evolutionary biology. See John Beatty, "What's Wrong With the Received View of Evolutionary Theory?”, in: PSA 1980, 2, 1981, pp. 397-426; Elisabeth Lloyd, The Structure and Confirmation of Evolutionary Theory. New York: Greenwood Press 1988; Thompson, The Structure of Biological Theories; and Peter Sloep, Wim Van der Steen, “The Nature of Evolutionary Theory: The Semantic Challenge”, in: Biology and Philosophy 2, 1987, pp. 1-15; as well as the different responses to this paper in Biology and Philosophy Vol. 2, No. 1.

40 Cf. for instance Mitchell, "Pragmatic Laws and Biological Complexity and Integrative Pluralism”, loc. cit.

41 Dizadji-Bahmani et al., "Who Is Afraid of Nagelian Reduction?”, loc. cit., p. 403. 
have strong company on their side. John Bickle clings to the view that reduction is a relation between theories but argues for a semantic conception of theories. ${ }^{42}$ Based on Clifford Hooker's approach to reduction ${ }^{43}$ Bickle formulates his "newwave account of intertheoretic reduction" ${ }^{44}$ according to which the reduction of one theory $T_{R}$ to another $T_{B}$ requires the construction of an "image $I_{B}$ of the settheoretic structure of models of the reduced theory $T_{R}$ within the set comprising reducing theory $\mathrm{T}_{\mathrm{B}}{ }^{\prime \prime 4}$. The details of Bickle's "semantic" account of intertheoretic reduction are complex. However, what matters for the purpose of my paper is that Bickle explicitly contrasts his approach with the Nagelian idea of "character-

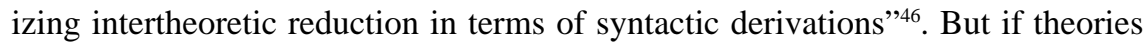
are understood as sets of models satisfying certain set-theoretic conditions and no longer as sets of sentences in an axiomatized system of first order logic it is no longer clear what Nagel's condition of derivability amounts to. It even more seems as if the proponents of the semantic view must abandon the claim that it is logical derivation that connects the reduced to the reducing theory and are in need of a different specification of the reductive relation between theories (for instance, according to Bickle, in terms of 'analogy' or 'isomorphism' between the image $I_{B}$ and the reduced theory $\mathrm{T}_{\mathrm{R}}$ ). ${ }^{47}$ The alternative would be to adopt a very broad (and thus vague) notion of 'derivation' that also captures the relation between sets of models. But such a vague concept of derivation runs the risk that too much can be derived from something else and, hence, does not appear to be convincing.

The preceeding discussion reveals that the combination of an account of intertheoretic reduction with a semantic conception of theories takes us too far away from the core ideas of the Nagelian understanding of epistemic reduction (in particular, from the second thesis of Nagel's general way of thinking about reduction, i.e. that the relation of reduction is logical derivation).$^{48}$ This does not imply that the combination is untenable, but only that the resulting account is not "Nagelian" anymore. Hence, switching to the semantic view of theories in order to meet the

42 Cf. Bickle, "Psychoneural Reduction: The New Wave and Philosophy and Neuroscience: A Ruthlessly Reductive Account”, loc. cit.

43 Cf. Clifford Hooker, "Towards a General Theory of Reduction. Part I: Historical and Scientific Setting. Part II: Identity in Reduction. Part III: Cross-Categorial Reduction”, in: Dialogue 20, 1981, pp. 38-59, 201-236, 496-529.

44 Bickle, "Psychoneural Reduction: The New Wave”, loc. cit., p. 23.

45 Bickle, "Philosophy and Neuroscience: A Ruthlessly Reductive Account”, loc. cit., p. 27.

46 Ibid.

47 Cf. Bickle, "Psychoneural Reduction: The New Wave”, loc. cit.

48 This claim is further confirmed by the fact that even explicit opponents of the Nagelian model of epistemic reduction adopt a semantic view of theories (see Carl Craver, "Structures of Scientific Theories“, in: Peter Machamer, Michael Silberstein (Eds.), The Blackwell Guide to the Philosophy of Science. Malden/Oxford: Blackwell Publishers 2002, pp. 55-79; "Beyond Reduction: Mechanisms, Multifield Integration and the Unity of Neuroscience”, loc. cit.; and "Explaining the Brain”, loc. cit.). 
second objection (i.e. the misrepresentation of the relata of reduction) is not an option for a proponent of Nagel's model of theory reduction.

Finally and most importantly, two further objections against Nagel's assumption that theories are the relata of reduction can be raised with respect to biology: first, biological research practice shows that, in general, theories are not the only and perhaps not the most important element of science. Second, biological practice reveals that for reduction, in particular, theories are only peripherally important since the most crucial and frequently occurring cases of epistemic reduction, i.e., reductive explanations, rarely involve fully explicated theories.

How could an opponent of the Nagelian account react to the first objection? As I have just argued, he must stick to the syntactic view of theories and, thus, is exposed to all the criticism that has been put forward against this conception. The overall tenor is: Because the syntactic view focuses on theories as a whole and on their inferential structure it fails to capture what biological theories in fact are ("theories in the wild" ${ }^{49}$ ). For instance, it does not account for the diversity of representations of theories biologists actually use and which are neither restricted to first order logical predicates nor to linguistic representations at all (see e.g. Laura Perini's work on the importance of diagrams in biology $\left.y^{50}\right)$. Second, the syntactic conception focuses on full-established, static theories (context of justification) and lacks an account of the dynamics of biological theories (context of discovery), that is, how they are developed over time and which roles they play during that time $^{51}$ Third, the syntactic view overestimates the role of theories by ignoring the important roles other epistemic units (such as models, descriptions of mechanisms, fragments of theories, etc.) play in the context of explanation, prediction, discovery, and manipulation in biology. The motivations for the development of the alternative, semantic conception of theories were to overcome these problems and to allow for the importance of models in scientific practice. I do not want to discuss the various versions of the semantic conception and the objections that can be put forward against them here. What is important for the topic of this paper is that even if a defender of the Nagelian model of reduction could adopt a semantic conception and could adjusts the notion of theories in a way that it is closer to what is going on in real biological research practice he still would not meet the first objection. Granted, theories (as sets of models) do occur in biological practice. However, theories are not the only and perhaps not the most important epistemic units in biology. To begin with, often not fully explicated theories as a whole, but rather fragments of theories, individual models and not entire sets

49 Craver, "Structures of Scientific Theories", loc. cit., p. 65.

50 Cf. Laura Perini, "Explanation in Two Dimensions: Diagrams and Biological Explanation”, in: Biology and Philosophy 20, 2005, pp. 257-269 and "Diagrams in Biology", in: Knowledge Engineering Review, forthcoming.

51 Cf. Lindley Darden, Theory Change in Science: Strategies from Mendelian Genetics. New York: Oxford University Press 1991 and Lloyd, "The Structure and Confirmation of Evolutionary Theory”, loc. cit. 
of models, and descriptions of particular mechanisms (if mechanistic models are understood as being parts of theories) ${ }^{52}$ play important roles in explanation, prediction, discovery, and manipulation. Second, in biological practice there seem to exist many epistemic units that are relatively independent from theories and that, nevertheless, are crucial for the successful functioning of the biological sciences, for example, explanatory and investigative strategies ${ }^{53}$, semi-empirical rules ${ }^{54}$, mechanistic models ${ }^{55}$, to list only a few. Finally and as a further substantiation of the previous thesis, some authors have argued that scientific models in general are better conceived as being independent from theories, rather than being constitutive of them..$^{56}$

The peripherality of theories to biological practice is even more apparent in the context of reduction. With respect to diachronic (or intralevel) reduction, Ken Waters has argued that a focus on theoretical developments fails to capture what is important for the successful transformation of biological disciplines, e.g., classical genetics. ${ }^{57}$ He suggests that philosophers should direct their attention to the changes in the investigative practices of genetics instead. I argue that we should abandon the Nagelian focus on theories as the only or most important units of epistemic reduction also with respect to synchronic (or interlevel) reduction. Rather, we should concentrate our analysis on the most crucial and frequently occurring kind of epistemic reduction in biological research practice, namely reductive explanations. Part-whole explanations and mechanistic explanations, which are the paradigmatic cases of reductive explanations, have been strongly connected with reduction for a long time - not only by philosophers but also by biologists themselves. ${ }^{58}$ However, individual explanations and the conditions that determine their reductive character have almost been neglected as a fruitful and independent subject of analysis so far. Granted, since Nagel took intertheoretic reduction to be a relation of explanation the debate about reduction has also been concerned with the issue of explanation. But discussions about explanation, which remain within the Nagelian framework, concentrate on the explanatory scope of theories

52 Cf. Craver, "Structures of Scientific Theories”, loc. cit.

53 Cf. Waters, "Beyond Theoretical Reduction and Layer-Cake Antireduction: How DNA Retooled Genetics and Transformed Biological Practice", loc. cit.

54 Cf. Sarkar, "Models of Reduction and Categories of Reductionism”, loc. cit.

55 Cf. Wimsatt, "Reductive Explanation: A Functional Account”, loc. cit., and Peter Machamer, Lindley Darden, Carl Craver, “Thinking about Mechanisms”, in: Philosophy of Science 67, 2000, pp. 1-25.

56 See for instance Mary Morgan, Margaret Morrison, Models as Mediators. Perspectives on Natural and Social Science. Cambridge: Cambridge University Press 1999.

57 Cf. Waters, "Beyond Theoretical Reduction and Layer-Cake Antireduction: How DNA Retooled Genetics and Transformed Biological Practice”, loc. cit.

58 To the philosophers belong, for instance, Wimsatt, "Reductive Explanation: A Functional Account”, loc. cit.; Sarkar, "Models of Reduction and Categories of Reductionism”, loc. cit.; and "Genetics and Reductionism", loc. cit., and to the biologists Ernst Mayr, “The Limits of Reductionism”, in: Nature 331, 1988, 475. 
(e.g. on the question whether physical theories can be employed to explain certain biological theories or biological phenomena) or on reduction as a relation between explanations, i.e. between a higher-level explanation and a lower-level explanation of the same phenomenon. ${ }^{59}$ Thus, they do not promote an understanding of what makes individual explanations reductive. Such an analysis would include the identification of the relata of reduction (roughly, explanandum and explanans) and the specification of the relation of reduction by analyzing the constraints on reductive explanations, that is, the various conditions on basis of which biologists evaluate the success and failure of the reductivity of explanations. ${ }^{60}$ In section 3.1 I claimed that an adequate account of epistemic reduction must capture and enlighten the cases of epistemic reduction that occur in actual biological research practice. According to this criterion of adequacy the fact that thinking about epistemic reduction in terms of theories and their logical relations does not yield an understanding of the reductive character of explanations is an important argument for the inadequacy of Nagel's general view of thinking about reduction. Thus, it seems fruitful to move beyond Nagelian reduction and shift the attention from theory reduction to reductive explanations. ${ }^{61}$

59 Cf. Rosenberg, "Darwinian Reductionism”, loc. cit.. Although Rosenberg explicitly abandons Nagel's model of theory reduction (Ibid., p. 40) his view of explanatory reductionism, nevertheless, remains closely connected to the Nagelian framework in a broad sense. For instance, he adheres to the view that laws are indispensable for explanation and his defense of explanatory reductionism is still centered on the question whether all biological phenomena can be explained with the resources of physical (or molecular) theory. See in particular Rosenberg "How Is Biological Explanation Possible?" and "Darwinian Reductionism”, loc. cit., ch. 4.

60 For an example of how such an analysis could look like see Marie I. Kaiser, "An Account of Explanatory Reduction in the Life Sciences“, in: History and Philosophy of the Life Sciences, forthcoming, Sarkar, "Genetics and Reductionism”, loc. cit., and Andreas Hüttemann, Alan Love, "Aspects of Reductive Explanation in Biological Science: Intrinsicality, Fundamentality, and Temporality”, in: British Journal for Philosophy of Science, forthcoming.

61 Although I am convinced that explanations are an especial fruitful subject of analysis I do not want to claim that giving an account of epistemic reduction by focusing on individual reductive explanations is the only possible way to analyze epistemic reduction in biology. Nor I want to argue that, on its own, it is sufficient to capture the diversity of reductive reasoning strategies present in current biology. Alternatively one could, for example, concentrate on methods (or investigative strategies) and try to specify what makes them reductive. This leaves room for the kind of pluralism Sarkar endorses: "There is no a priori reason to assume that all cases of reduction are so similar that they can all be captured by any single model of reduction.” (Sarkar, "Models of Reduction and Categories of Reductionism", loc. cit., p. 188). In this pluralistic picture also the Nagelian account of theory reduction could have its place - though it would be a very small place, as my discussion shows. 


\subsection{The Focus on Formal Issues}

It is important to note that the criticism of Nagel's model of theory reduction (as well as the criticism of the syntactic view of theories and of the D-N model of explanation) is a part of a more general rejection of the logical empiricist's kind of philosophy, which focuses on formal issues (like the logical relations between sentences formalized in first order logic) and thereby ignores "substantive issues" ${ }^{2}$. The attack against this kind of philosophy and the effort to replace it has a long history. However, as I pointed out in section 2, in the context of reduction Nagel's formal model has shown a long persistency.

In this section I want to call attention to two issues: first, I argue that the logical empiricist's formal philosophy can only be rejected as a whole packet. Second, in addition to the criteria I have already identified (see section 3.1) there is a third criterion of adequacy for an account of epistemic reduction, according to which a formal model of reduction like Nagel's comes away badly. Let us start with the first point. In his work on reductive explanations in genetics, Sarkar emphasizes that his analysis of what makes explanations reductive entails no commitment to a specific explication of what an explanation is (despite a few "basic assumptions" ${ }^{33}$ ). Rather, he tries to "keep the issues of reduction and explanation distinct" and identifies "additional criteria" 64 an explanation must satisfy in order to be a reductive explanation. I embrace Sarkar's goal not to conflate the question of what makes a representation (or a model) explanatory and, thus, distinguishes it from purely descriptive representations with the question of what makes an explanation reductive and distinguishes it from non-reductive explanation. I will come back to this issue when I present my third criterion of adequacy. What I think is important to note is that drawing this distinction between the issues of explanation and reduction and focusing exclusively on the latter does not guarantee that the provided account of epistemic reduction is neutral with respect to what the adequate model of explanation is. In fact, contrary to his own assertion, Sarkar's analysis cannot preserve the asserted neutrality. The reason is that Sarkar rejects Nagel's model of theory reduction because of its focus on "formal issues, [i.e.] the 'logical' form of reduction”65 and wants to replace it with an analysis of "substantive issues" (i.e. what reductive explanations "assume about the world"), which he conceives to be "more interesting and important" ${ }^{66}$ However, exactly this criticism seems to abolish the possibility of adopting a D-N (and I-S) model of explanation. At least, it seems to be very weird to reject Nagel's model because of its focus on formal issues, yet to adhere to the formal D-N model of explana-

62 Sarkar, “Genetics and Reductionism”, loc. cit., p. 19.

63 Ibid., p. 41.

64 Ibid., p. 9.

65 Ibid., p. 17.

66 Ibid., p. 18f. 
tion that encounters very similar objections ${ }^{67}$ What has also become apparent in the discussion about the structure of scientific theories in section 3.2: If you reject Nagel's account of theory reduction because of its formal character and you want your whole philosophical position to be consistent you better get rid of the whole packet, including the D-N model of explanation and the syntactic view of theories.

Let us turn to the second issue. The discussion of Sarkar's approach revealed a third criterion of adequacy an account of epistemic reduction in biology must satisfy, namely to demarcate cases of epistemic reduction from cases where there is no reduction at all. With respect to reductive explanations (which a model of epistemic reduction must account for, see section 3.2) this amounts to providing one or several demarcation criteria on basis of which reductive explanations clearly can be distinguished from explanations that are non-reductive. In sum:

A model of epistemic reduction should

(3) demarcate reductive explanations from non-reductive explanations.

Nagel's formal model of theory reduction fails to meet this criterion since it equates explanation (of one theory by another) with reduction. As soon as a theory can be explained by and (according to the D-N model of explanation) thus be logically derived from another theory we have a case of theory reduction. What is important from Nagel's perspective is whether the two formal criteria, derivability and connectability, are satisfied or not. ${ }^{68}$ But this does not endow us with resources to distinguish explanations of phenomena (types as well as tokens) that are reductive from those that are non-reductive. In order to draw this line of demarcation we need to refer to the relations that exist between the things in the world described in the explanandum and explanans in an explanation. For instance, we need to make claims of the kind that in many reductive explanations the entities referred to in the explanans are located on a lower, more fundamental level than (level fundamentality) or are internal to (internal fundamentality) the system whose behavior is to be explained. ${ }^{69}$ Only thinking about epistemic reduction in a non-formal way directs our attention to these crucial substantive issues.

Finally, let me mention a related point. In so far as an analysis of the reductive character of biological explanations reveals that the reductivity of an explanation is not an "all-or-nothing phenomenon" ${ }^{\text {", }}$ it succeeds much better than the Nage-

67 This is why most of the early opponents of Nagel's model of theory reduction endorse a causal-mechanistic account of explanation (see e.g. Hull, "Philosophy of Biological Science", loc. cit., and Wimsatt, "Reductive Explanation: A Functional Account, loc. cit.).

68 As I mentioned before, Nagel also proposed some non-formal conditions for theory reduction (cf. Nagel, “The Structure of Science”, loc. cit., pp. 358-366). However, these criteria help to distinguish trivial from non-trivial cases of theory reduction but they do not provide the demanded demarcation of reductive from non-reductive explanations.

69 Cf. Kaiser, "An Account of Explanatory Reduction in the Life Sciences“, loc. cit.

70 Cf. Hüttemann, Love, “Aspects of Reductive Explanation in Biological Science: Intrinsicality, Fundamentality, and Temporality”, loc. cit. 
lian approach in capturing the diversity and complexity of epistemic reduction (second criterion of adequacy, see section 3.1). According to Nagel, a theory can either be deductively derived from and thus be reduced to another theory or it cannot. In a specific case there are just two options: either reduction succeeds or it fails. Focusing on reductive explanation discloses that the situation in actual biological research practice is not as simple as suggested by Nagel's account. In fact, different respects in which an explanation can fail or succeed to be reductive need to be kept apart. ${ }^{71}$ This important fact is obscured by Nagel's focus on theories and the logical relations between them.

\section{Conclusion}

Even if one grants that the proponents of the Nagelian model of theory reduction can handle several problems that have been raised in the past, Nagel's general way of thinking about epistemic reduction in terms of theories and focused on formal issues still remains inadequate with respect to what epistemic reduction in biology really is. In order to show this, I identified three criteria of adequacy and argued why Nagel's account fails to meet any of these criteria. First, it does not capture and enlighten those cases of epistemic reduction that are most important and frequently occurring in biological practice since it identifies relata, i.e., (fully-established) theories, that are not as important in biology as suggested, since it focuses on cases of epistemic reduction that are peripheral to biology, since it fails to account for the most crucial kind of epistemic reduction, i.e. reductive explanations, and since it focuses on formal issues and thereby ignores important substantive issues. Second, because of its restricted focus on formal issues and on theories, the Nagelian approach fails to account for the diversity of the cases of epistemic reduction that are present in contemporary biology as well as for the complexity of the conditions that determine the reductivity of biological explanations. Third, Nagel's account does not provide the recourses to demarcate reductive explanations from non-reductive explanations. All this strongly suggests that it is finally time to move beyond the Nagelian framework and break new ground in thinking about epistemic reduction.

Universität zu Köln

Philosophisches Seminar

Richard-Strauß-Straße 2

50931 Köln

kaiser.m@uni-koeln.de

71 See also ibid. 